\title{
A importância da Tecnologia da Informação na indústria de construção naval: um estudo de caso
}

\author{
Newton Narciso Pereira \\ Centro Universitário Monte Serrat - Santos \\ Fernando José Barbin Laurindo \\ POLI-USP
}

\begin{abstract}
Resumo
Este artigo tem por objetivo apresentar como o uso da Tecnologia da Informação (TIJ pode trazer impactos na indústria de construção naval. A base teórica visa estabelecer como a TI fornece suporte no dia-a-dia dos estaleiros no Desenvolvimento de Novos Produtos (DNP) "embarcações" e no Gerenciamento de Projetos (GP), maximizando a redução de custos e de tempo de projeto e construção de embarcações, melhorando a qualidade do produto final.

$\mathrm{O}$ artigo foi realizado com a abordagem metodológica de estudo de caso, tendo como base dados levantados a partir de pesquisa de campo, com realização de entrevistas e visitas às instalações do estaleiro para colher as informações e elaborar o estudo de caso.
\end{abstract}

\section{Palavras-chave}

Desenvolvimento de novos produtos, tecnologia da informação e gerenciamento de projetos.

\section{The importance Information Technology in the industry of naval construction: a case study}

\begin{abstract}
This article has for objective to present the use of the Information Technology in the industry of naval construction. The theoretical bases aims at to establish as IT supplies to support in the shipyards day-by-day of the in the New Development Product (NDP) "boats" and in the Project Management (PM) maximizing the costs reduction and time of project and construction of boats, improving the final product quality.

The paper was developed through case study methodological approach and based in data taken from field research, performed through interviews and visits to shipyard installations in order to gather information and elaborate a case study
\end{abstract}

Key words

New product development, information technology and management project. 


\section{INTRODUĈ̣̃O}

Atualmente, a competitividade entre as empresas de construção naval é determinada pela qualidade de seus recursos, pelo conhecimento que são capazes de produzir e pela capacidade de aplicar ciência, tecnologia e conhecimento na produção de embarcações cada vez mais eficientes. As políticas adotadas para atender tais requisitos requerem investimentos por parte dos construtores navais na aquisição de softwares que viabilizem a utilização das mais modernas práticas de engenharia. Os sistemas existentes para Integrar Produtos e Desenvolvimento de Processos (IPDP), Engenharia Simultânea (ES), e Gerenciamento da Qualidade Total (GQT) têm produzido um sucesso notável nessas organizações.

Neste contexto, a Tecnologia da Informação (TI) é vista como um elemento catalisador da integração ciência e aplicação tecnológica dos avanços na construção naval. Na visão do clássico texto de Porter e Millar (1985) já era destacado que a TI deve ser entendida de maneira ampla, como uma matriz que une tecnologias cada vez mais convergentes e interligadas, que processam informações. Além dos computadores, estão envolvidos neste contexto, sensores, radares, GPS, tecnologias de comunicações, automação e outros hardwares.

Estes desenvolvimentos estão presentes no setor de construção naval, onde a TI melhora o Desenvolvimento de Novos Produtos (DNP), no caso "embarcações", bem como no Gerenciamento de Projeto (GP). Os impactos positivos da TI no DNP e no GP podem ser alcançados de diferentes formas, com a implementação de banco de dados, elaboração de software com plataforma CAD/CAE/CAM e controle de projetos (como, por exemplo, o Microsoft Project) interconectando e acompanhando outros processos de desenvolvimento (LAURINDO; CARVALHO, 2005). Sendo assim, a TI pode atuar também nos processos administrativos e no ambiente global da empresa.

O potencial que a TI tem de realizar estas mudanças varia de acordo com as características do processo (cadeia de valor) e do produto, no tocante à necessidade de informação. Em empresas cujos produtos e processos contêm muita informação, os sistemas de informação vão ter grande importância (PORTER; MILLAR, 1985). Apesar dos questionamentos quanto ao uso estratégico da TI (CARR, 2003), o impacto da TI tende a ser mais significativo quando seu uso está associado à alteração nos processos da empresa (FARRELL, 2003).

Segundo Hallows (2002), a TI fornece suporte aos grandes, pequenos e médios estaleiros, que estão percebendo os benefícios que um consistente gerenciamento de DNP e GP podem proporcionar.
Assim sendo, o objetivo do artigo é compreender os impactos das aplicações de TI na indústria de construção naval, em especial analisar como ocorreu o impacto da TI na estrutura organizacional de um estaleiro de médio porte, avaliando os processos de DNP, GQT e GP antes e depois da implantação da TI. A metodologia adotada foi a de estudo de caso. Além disso, o presente artigo pretende identificar o retorno do investimento (considerado em termos qualitativos) em TI na forma de ganhos em produtividade e interações no projeto. Isto considerando os aspectos humanos e o envolvimento da alta gerência na estratégia de TI e os fatores críticos de sucesso que garantem a sobrevivência da empresa no mercado competitivo de construção de embarcações de esporte e recreio.

\section{s políticas adotadas para atender tais requisitos requerem investimentos parte dos construtores navais na aquisição de softwares.}

\section{REFERENCIAL TEÓRICO}

\section{Tecnologia da Informação}

A TI pode ser definida como a convergência da eletrônica, computação digital e telecomunicações. O uso da TI desencadeou uma onda de inovações tecnológicas em coletar, armazenar, processar, transmitir e apresentar informações (TURBAN et al., 2004). Todos os setores da economia exercem influência, através de suas demandas específicas, no desenvolvimento de aplicações TI, pois esta abriu as portas para o crescimento de novas oportunidades de negócios, permitindo a maior flexibilidade no processo de DNP e GP. Os desenvolvimentos de novos sistemas de informação são constantemente implantados para melhorar a produção, qualidade e eficiência das empresas, tanto nas áreas administrativas como de manufatura e qualidade, permitindo o controle de máquinas e robôs (LAUDON; LAUDON, 2004; LUTCHEN, 2004; LUFTMANN, 2003).

Neste sentido, Laurindo (2005) explica que a Tecnologia da Informação (TI) é vista como o fator de viabilização desta integração em abrangência mundial, bem como a criação de novas estratégias de negócio, estruturas organizacionais e formas inovadoras de relacionamento entre empresas e seus consumidores. Na visão de Porter (2001), a TI é uma poderosa ferramenta para enfatizar uma estratégia distintiva e, neste aspecto, está apoiada em três pilares. No primeiro, permite o desenvolvimento de novos produtos e a eficiência em novos processos. No segundo, facilita a rápida difusão das inova- 
ções. Finalmente, no terceiro possibilita a economia de escala que beneficia rapidamente a expansão do uso da TI.

Deste modo, os diferentes papéis desempenhados pela TI dentro de uma empresa podem ser vistos na classificação realizada por McFarlan (1984), em que o autor propõe o Grid Estratégico. Este é uma ferramenta que permite visualizar a relação entre a estratégia de TI (atual) e a carteira de aplicações (futura), definindo quatro regiões, cada qual identificando um possível papel da TI na organização, sendo que estes papéis são vistos como: Suporte, Fábrica, Estratégico e Transição.

Segundo Moraes e Laurindo (2003), as aplicações de TI em empresas classificadas como Suporte têm pouca influência na estratégia da empresa. Já para aplicações de TI em empresas classificadas como Fábrica, são importantes para o sucesso da operação da empresa, mas elas não prevêem aplicações para o futuro. Empresas que adotam como caráter estratégico aplicações de TI consideram-na muito importante para a estratégia atual dos negócios e novas aplicações planejadas tendem a manter a sua importância no futuro. Por outro lado, para algumas empresas a TI pode representar um papel de transformação, isto é, as aplicações estão saindo de uma situação de baixa importância "Suporte", para assumir um papel de importância estratégica na organização em face das novas aplicações planejadas para o futuro, por isso está em "Transição", conforme mostrado na Figura 1.

Note-se que Nolan e McFarlan (2005) rediscutiram o Grid Estratégico, destacando que as empresas situadas nos quadrantes Suporte e Fábrica adotam uma postura defensiva quanto ao uso da TI, enquanto que aquelas que estão classificadas nos quadrantes Transição e Estratégico assumem uma postura ofensiva em relação ao uso da TI.

O Grid Estratégico permite tirar algumas conclusões importantes do posicionamento da empresa em relação ao uso da TI e à forma como ela é gerenciada. Entretanto, muitas empresas em todos os setores ainda não conseguiram atingir o retorno esperado com a implementação da TI por vários motivos.

Assim, MacDonald et al. (2000) afirmam que o chamado paradoxo da produtividade em TI é percebido devido a uma discrepância existente entre os investimentos em TI e a performance no dia-a-dia. Segundo Brynjolfsson e Hitt (2003), algumas empresas gastam grandes quantias em TI obtendo pequeno retorno, enquanto que outras gastam quantias similares com grandes benefícios. No entanto, já foram apresentadas várias justificativas para o paradoxo da produtividade (BRYNJOLFSSON; HITT, 1998). Entre elas, é destacado que se encontram reais ganhos com os investimentos em TI, principalmente quando associados com mudanças nos processos empresariais (FARRELL, 2003).

Deste modo, a TI tem que ser bem entendida e implementada em alinhamento com a estratégia e as operações da empresa, de maneira gradual para que possa trazer benefícios para a empresa, em todos os seus setores, principalmente no desenvolvimento de novos produtos para atender a um mercado cada vez mais competitivo e exigente.

Figura 1: Grid estratégico: Impacto das aplicações de TI.

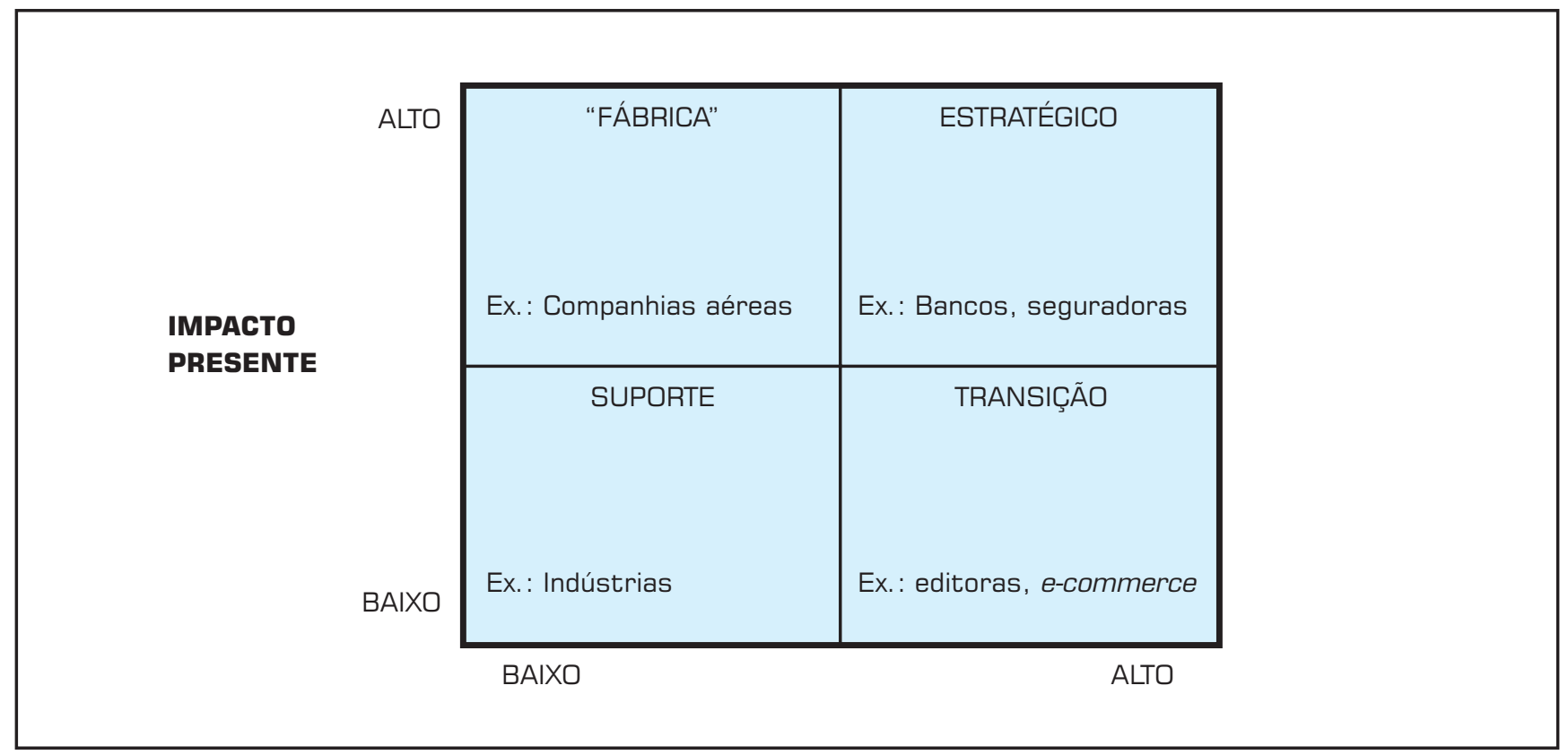

Fonte: Laurindo, 2005. 


\section{Desenvolvimento de novos produtos}

O desenvolvimento de novos produtos nos últimos anos tem se tornado um dos pontos principais na competição entre empresas de todo mundo. Esta tendência mundial teve origem após a Segunda Guerra Mundial e mais intensamente ao longo das décadas de 1970 e 1980, em que muitas empresas espalhadas pelo mundo passaram a ampliar o espaço competitivo além de suas fronteiras territoriais (DIAS, 2005). Além disso, as empresas passaram a atender mercados fragmentados com demandas específicas e, com o advento de novas tecnologias, como a microeletrônica e as tecnologias de informação, cresceram as necessidades de novos produtos mais sofisticados, com diferenciais tecnológicos.

Em sintonia com esta visão, Juran (1992) já definia DNP como um processo experimental que muda as características dos produtos correspondendo às necessidades do cliente. $\mathrm{O}$ autor estabelece também que o projeto de um produto é o processo que define as características principais deste para atender ao anseio do mercado no qual a empresa está inserida. O DNP deve ser visto como um conjunto de dados teórico-empíricos, confinados pelo tempo, sendo tratado e modificado para atender os requisitos estabelecidos pelo cliente (POSSAMI; FUTAMI; VALENTINA, 2002), conforme mostrado na Figura 2.

A Figura 2 mostra que o processo de desenvolvimento de um produto passa por diversas etapas, em que são gerados diversos ciclos de aprendizado tanto para a organização quanto para os membros envolvidos no desenvolvimento (PEREIRA; LAURINDO, 2006). Segundo Woodham (1997), para os projetistas aplicarem seus conhecimentos no DNP é necessário não apenas o conhecimento em áreas tradicionais semelhantes aos materiais e processos de fabricação, mas também ter conhecimento sobre as estratégias de marketing e entender as expectativas do cliente. Davenport et al. (1995) relatam que renovar o processo de DNP não é simplesmente fazer uma reengenharia nos processos de desenvolvimento utilizados, pois envolve também mudanças nos processos de fabricação e qualidade. A atividade de DNP consiste na mutação dos atributos do produto visando novas soluções, que demonstre a capacidade da equipe de desenvolvimento em pensar diferentemente do usual (PAPANEK, 1971).

Deste modo, a equipe de desenvolvimento deve estar atenta ao surgimento de inovações tecnológicas, pois a inovação dos produtos é um elemento crucial de vantagem competitiva, garantindo a participação de uma fatia de mercado, bem como manutenção de clientes ávidos por novidades, gerando, portanto, retornos de investimentos para as empresas (RABECHINI JR. et al., 2002).

Pereira e Laurindo (2006) destacam que a inovação tecnológica aplicada ao desenvolvimento de novos pro-

\section{Figura 2: Modelo de atividade de DNP.}

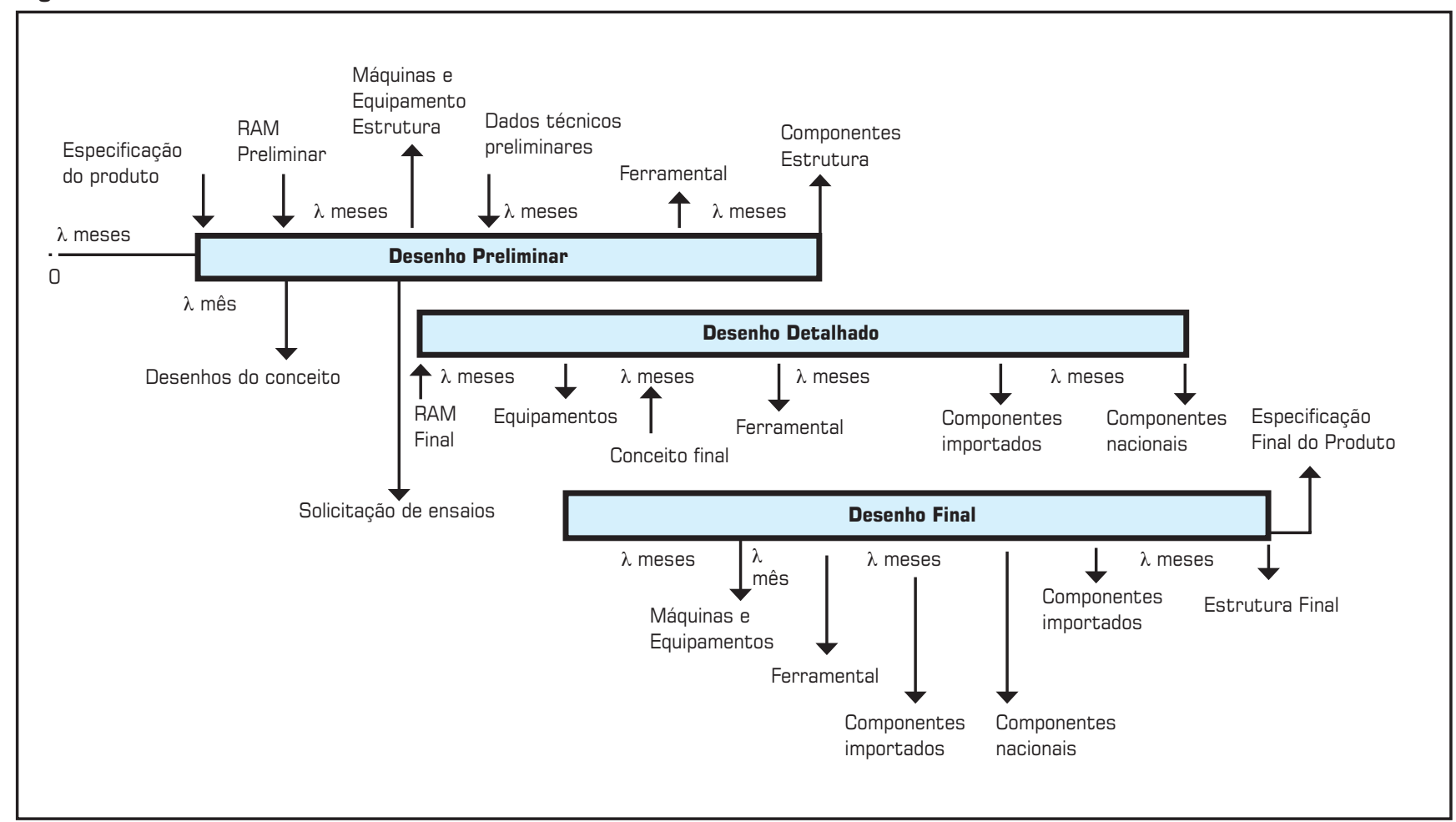

Fonte: Adaptado de Possami; Futami; Valentina, 2002. 
dutos, tem grande importância numa economia baseada no conhecimento, que incorpora maior grau de exigência aos produtos desenvolvidos. Assim, para atender os requisitos dos mercados globalizados, as empresas podem utilizar inovações tecnológicas tais como ferramentas Computer-Aided Design (CAD), Computer-Aided Engineering (CAE) e Computer-Aided Manufacturing (CAM) que melhoraram significativamente a eficiência do DNP, o processo de fabricação, além de permitir maior flexibilidade para implantação de novos projetos (LAURINDO; CARVALHO, 2005).
Oliveira (2003) explica que a partir da década de 1950, as técnicas de GP passaram a ser formalmente estudas e catalogadas, sendo que até a década de 1990, a gestão de projetos não passava de mais uma teoria, julgada por muitos como incipiente e arriscada, uma vez que não havia experiência na sua aplicação, exceto na área militar, e a mesma era entendida como uma ameaça à estrutura organizacional existente. A partir da década de 1990, esta idéia começou a mudar e as empresas começaram a utilizar-se de técnicas que pudessem auxiliá-las a maximizar tempo, melhorar sua eficiência e satisfazer seus clientes, pois é inevitável, atualmente, criar produtos com qualidade, em prazos e com preços cada vez menores, com consumidores cada vez mais exigentes.

Assim, para viabilizar esse processo, diversos softwares de gerenciamento de projeto permitem a aplicação de técnicas como Critical Path Method (CPM) e Program Evaluation and Review Technique (PERT) para o controle das atividades e etapas dos projetos. Segundo Cukierman (1978), PERT/CPM consiste em figurar o projeto numa rede ou grafo onde se representam ações de acordo com as respectivas relações de correspondência. PERT é uma ferramenta de gerenciamento de projetos usada para programar, organizar e coordenar tarefas. A metodologia PERT foi desenvolvida pela marinha americana em 1950 para gerenciar o programa de construção do submarino Polaris. O CPM foi desenvolvido para gerenciar projetos no setor privado e surgiu na mesma época que a metodologia PERT, assim as técnicas ficaram conhecidas como PERT/CPM.

Ambos os métodos são muito utilizados no dia-a-dia dos estaleiros, tendo em vista o fato de que o navio é uma das estruturas mais complexas já construídas pelo homem, já que seu projeto envolve profissionais dos vários segmentos da engenharia e milhares de atividades são realizadas até o navio ser construído (ALLMENDINGER, 1983).

\section{Virtualização do DNP e GP}

O desenvolvimento mais ágil de produtos tornou-se uma questão crítica para o sucesso em muitos setores do mercado, para uma grande variedade de produtos. Isto motivou o desenvolvimento de técnicas de engenharia simultânea na década de 1980, capazes de reduzir o tempo de ciclo, com base na sobreposição temporal de atividades de projeto, a serem executadas em paralelo, sempre que possível (FORD; STERMAN, 1999). Entretanto, as restrições físicas dificultam a realização de diversas tarefas de projeto, como projetar, construir, testar e aceitar o protótipo de um produto, conforme preconizado pela engenharia simultânea.

Para minimizar este processo, surge a simulação como uma maneira eficaz de representar sistemas, plantas, ou as 
políticas propostas para o teste preliminar, antes de desenvolver protótipos caros, testes de campo ou execuções reais. De acordo com McGoveran (2004), a validade da simulação depende da representação exata das características operacionais do processo criado. Na engenharia, deve-se considerar o auxílio do computador em tarefas de projeto, permitindo a aceleração do desenvolvimento e a otimização dos recursos envolvidos.

Os modelos empregados para representar um ambiente real em modelo virtual são elaborados através de formulações matemáticas, que devem reproduzir, da maneira mais fiel possível, os efeitos físicos característicos do sistema original. Assim, manipulando o modelo no computador e analisando os resultados, pode-se concluir como os diversos fatores afetarão o desempenho do sistema, uma vez que no final das simulações um protótipo precisa ser construído, para que o produto possa ser testado e operado, para confrontar os dados reais com os criados em ambiente virtuais, conforme observa (JONS, 1997).

Os ambientes de Realidade Virtual $(R V)$ aplicados a atividades de projeto originaram-se da convergência entre os avanços da tecnologia de eletrônica digital utilizada em computadores e as evoluções da tecnologia de apresentação visual (JONS, 1997). A realidade virtual ganhou fama através dos filmes de ficção científica; entretanto, o custo elevado restringia tal tecnologia inicialmente à indústria bélica. Esta tecnologia engloba diversas áreas do conhecimento, tais como a computação, eletrônica e robótica, permitindo a imersão e a interação dos usuários, para que eles possam criar protótipos e visualizá-los em um cenário gerado em tempo real pelo computador (MACHADO, 2003).

Atualmente, esses graus de imersão e interação influenciam no nível de realismo do modelo virtual, assim como, para obter maior precisão, laboratórios utilizam informações coletadas através de sensores tridimensionais instalados em modelos reais reduzidos, que capturam seu movimento repassando-o para o computador, que constrói o protótipo virtual, conforme apresentado na Figura 3.

Assim, é cada vez mais fácil criar imagens gráficas realistas e transmiti-las para que possam ser rapidamente apresentadas com qualidade próxima à de uma fotografia, podendo ser utilizadas por outras pessoas ou equipes envolvidas em um projeto. Os principais desenvolvimentos nesta área estão ligados a: projeto baseado em simulação (simulation based design), prototipação virtual (virtual prototyping), realidade virtual (virtual reality) e projeto colaborativo a distância (workflow). Protótipos virtuais realizados em $\mathrm{CAD}$, com recursos de $3 \mathrm{D}$, podem ser facilmente montados e desmontados virtualmente, permitindo estudos muito mais detalhados, repetidos quantas vezes se julgar necessário (CSILLAG e GRAEML, 2004). A Figura 4 apresenta um ambiente de realidade virtual no qual está sendo estudado o comportamento de um navio de guerra.

A rapidez com que podem ser realizadas alterações nos protótipos virtuais e o baixo custo dessas alterações estimula a realização de mais ensaios, com configurações alternativas das peças que estão sendo projetadas. Isto permite que produtos de melhor qualidade demorem menos tempo para ser desenvolvidos e colocados no mercado.

Um exemplo bem-sucedido de projeto completamente baseado em protótipos virtuais é o da marinha americana, que adquiriu um software da empresa Intergraph (2004), para o projeto e construção do navio anfíbio Sant Antonio. $\mathrm{O}$ projeto envolveu equipes multifuncionais espalhadas ao redor do país, que trabalharam de forma simultânea sobre protótipos virtuais. Para Kroo (1996), um dos grandes benefícios potenciais ainda não concretizados a partir da realização de projetos baseados em simulação é a possibilidade de incorporar, desde os primeiros estágios do desenvolvimento do projeto, requisitos e objetivos multidisciplinares e inter-

Figura 3: Geração de protótipo virtual a partir de modelo real reduzido (bulbo de um navio).

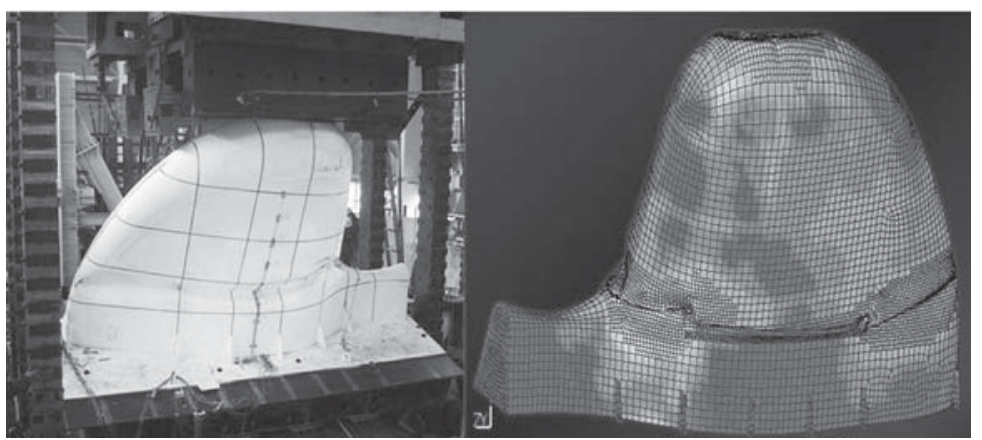


departamentais, nos quais os protótipos virtuais podem fazer a diferença mais significativa.

Segundo a Intergraph (2004), a virtualização em 3D, permite a visualização do processo construtivo da embarcação, simulando operações e testando o produto antes da construção. A Intergraph (2004), explica que a utilização de modelagem 3D e 4D reduz custos e aumenta o rendimento. Durante a fase de construção da embarcação o uso dos recursos virtuais auxilia a equipe de produção a encontrar possíveis falhas e corrigi-las, reduzindo o tempo gasto com o retrabalho.

A Intergraph (2004) publicou que o departamento de defesa americano obteve uma economia de US\$186 milhões e a diminuição substancial no retrabalho durante a fase de construção do navio anfíbio. Tan e Bligh (1998) afirmam que as simulações virtuais das fases de construção de um navio podem reduzir cerca de $40 \%$ do tempo gasto com o retrabalho e a correção de falhas.

\section{Fatores críticos de sucesso}

De acordo com a definição de Rockart (1979), os fatores críticos do sucesso (FCS) representam um conjunto de determinadas áreas que, se apresentarem resultados satisfatórios, garantirão um desempenho competitivo de sucesso para a empresa. Segundo Rockart (1979), os fatores críticos de sucesso estão relacionados com a estrutura interna da empresa, a indústria em que atua, localização e posicionamento estratégico da empresa nesta indústria.

No que tange aos FCS na implementação de projetos nas empresas, o estudo apresentado por Rabechini Jr. et al. (2002) mostra a visão de um grupo de 50 gerentes que perceberam dez fatores críticos essenciais para o sucesso dos projetos: missão do projeto, suporte gerencial, planejamento, cliente consultor, questão de administração de pessoal, tarefas técnicas, aceite do cliente, monitoramento, comunicações e gerência conciliadora.
Sobre estes fatores, os autores apresentam que: a missão do projeto é a definição clara dos objetivos no início do projeto para toda equipe envolvida; suporte gerencial trata-se da autoridade e poder existente na organização para gerir os recursos disponíveis; planejamento refere-se ao estabelecimento de metas individuais do projeto; cliente consultor trata da comunicação com os clientes; questão de administração de pessoal relaciona-se com a alocação, recrutamento e seleção de pessoal; tarefas técnicas envolvem as questões técnicas do projeto; aceite do cliente trata-se do estágio final do projeto e venda dos resultados; monitoramento do fornecimento de feedback em todos os estágios do projeto; comunicação é a criação de uma rede de transmissão das informações sobre o projeto e, finalmente, gerência conciliadora é uma equipe capaz de superar as inesperadas crises durante o decorrer do projeto, conciliando as expectativas dos interessados.

Diante destes fatores, Patah (2004) destaca que para atingir os FCS no desenvolvimento de projetos, estes devem estar pautados na eficiência e na eficácia, bem como nos aspectos de maturidade organizacional. Sendo assim, os FCS são ligados à estratégia da empresa e dependem da vontade política dos envolvidos, bem como da adequação da estrutura organizacional e do planejamento estratégico, tático e operacional.

\section{ASPECTOS METODOLÓGICOS}

Como já destacado anteriormente, o objetivo deste artigo é compreender como as aplicações de TI podem trazer impactos na indústria de construção naval, em especial analisar como ocorreu o impacto da TI na estrutura organizacional de um estaleiro de médio porte, avaliando os processos de DNP, GQT e GP antes e depois da implantação da TI.

Assim, o presente artigo adotou a abordagem metodológica de estudo de caso, em face da natureza exploratória

\section{Figura 4: Virtualização do comportamento de um navio.}
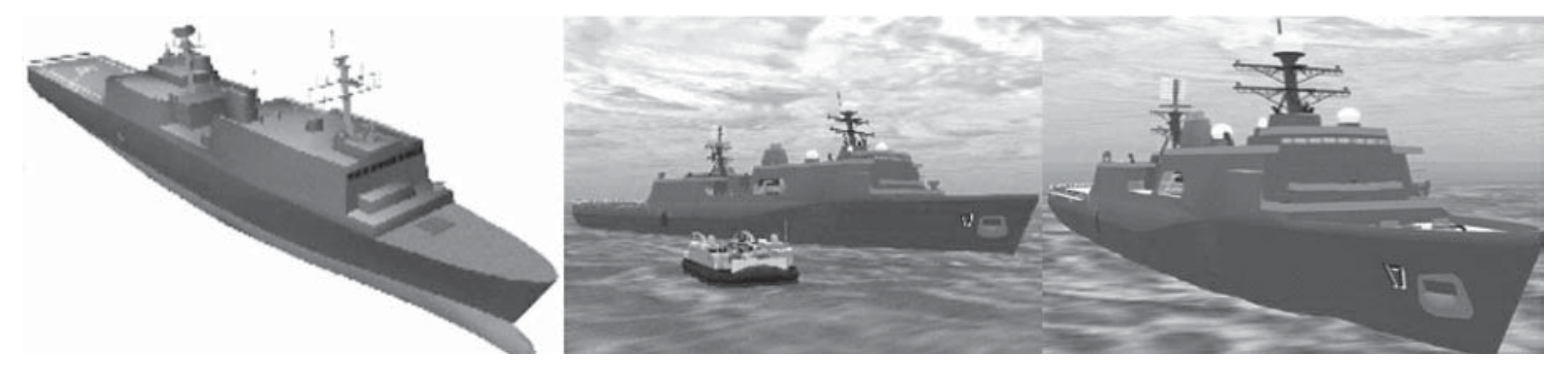
da pesquisa e das questões que se buscou investigar (YIN, 1991). Conforme destacaram Claver et al. (2000), o estudo de caso é metodologia adequada para várias pesquisas na área de TI, devido, entre outros fatores, às constantes mudanças que ocorrem neste ramo do conhecimento.

Com intuito de atingir os objetivos deste artigo, o embasamento teórico discutido anteriormente destacou os seguintes pontos principais:

- A competição entre as indústrias globais de construção naval acirram a concorrência entre os estaleiros, fazendo com que busquem maneiras de se diferenciar no mercado através de redução de custos e adoção de tecnologia;

- A TI como ferramenta importante do desenvolvimento de novos produtos, contribuindo significativamente para a melhora dos processos produtivos e gerenciamento de novos projetos;

- As atuais aplicações de TI permitem utilizar-se de modelagem 3D, através de ferramentas CAD na construção de modelos virtuais, fornecendo agilidade, redução de tempo de testes, custos e falhas. Segundo Porter (1986), o DNP é vital para as companhias que adotam este processo como meio de diferenciação e o utilizam como vantagem competitiva.

Com base nos conceitos expostos acima, foi realizado um estudo de caso de forma exploratória em um estaleiro, no qual se puderam avaliar os impactos da TI nos processos de DNP e GP. Para selecionar a empresa para o estudo de caso foram analisados os seguintes critérios:

- Importância estratégica da TI no DNP e GP para o estaleiro;

- A TI como ferramenta para a melhoria da eficácia e eficiência no DNP e GP.

As informações para elaboração do estudo de caso foram obtidas através de entrevistas realizadas no estaleiro, com os gerentes de produção, qualidade e projetos da empresa, sendo considerados os seguintes aspectos:

- Características da empresa;

- Avaliação dos recursos CAD/CAE/CAM;

- Investimento em TI e recursos humanos;

- Aplicação da TI no DNP e GP;

- Retorno do investimento em TI.

As perguntas foram realizadas em duas etapas. Na primeira etapa, foram entrevistados os gerentes de projetos e do setor administrativo e, na segunda fase, foram os gerentes de produção e qualidade das instalações fabris. As questões realizadas tiveram o intuito de identificar o posicionamento do papel da TI na empresa, segundo o critério estabelecido por McFarlan (1984), isto é, em qual quadrante do Grid Estratégico o estaleiro estaria inserido, conforme mostrado na Figura 1. Durante a condução das perguntas foi possível discutir com os gerentes quais são os fatores críticos de sucesso para o estaleiro, segundo o modelo de Rockart (1979).

\section{ESTUDO DE CASO}

\section{A empresa}

$\mathrm{O}$ estudo de caso foi realizado no estaleiro Alpha, de médio porte, que atua no segmento de esporte e recreio, produzindo lanchas, embarcações de pesca e iates de alto padrão. O estaleiro Alpha foi fundado em 2004, após o desmembramento de dois estaleiros conceituados no segmento naval e, atualmente, pertence a um grupo de empresas, com mais de 10 anos de existência, que atuam nos mercados de construção civil, projetos especiais para indústria química, petroquímica e plataformas off-shore.

\section{urge a simulação como uma maneira $\checkmark$ eficaz de representar sistemas, plantas, ou as políticas propostas para o teste preliminar.}

Com o desmembramento, o estaleiro Alpha passou a ter posse dos moldes para a construção dos cascos de fibra de vidro desenvolvidos por um arquiteto naval cujos moldes são consagrados do mercado. Estes moldes são conceituados no meio naval devido a suas características hidrodinâmicas, permitindo que as embarcações tenham um bom desempenho quando estão em operação. No mercado de embarcações de esporte e recreio este é um diferencial importante, pois um dos requisitos exigidos pelos compradores é a velocidade da embarcação (PEREIRA; SAMPAIO, 2005)

O estaleiro Alpha está situado em São Paulo e emprega 80 funcionários em suas instalações, que ocupam uma área de $6000 \mathrm{~m}^{2}$. Os principais produtos fabricados são as lanchas de $32,33,38$ e 50 pés. A produção atual é de duas embarcações por mês, todas construídas em fibra de vidro, e, para o ano de 2006, o quadro de pedidos já estava completo quando da realização das entrevistas. O estaleiro Alpha tem como diferenciais competitivos o preço e o atendimento das necessidades de cada cliente. Segundo os critérios estabelecidos por Porter (1985), o estaleiro trabalha com a estratégia competitiva voltada a diferenciação dos produtos, onde os clientes podem participar da fase de projeto, sendo que a empresa trabalha sob encomenda dentro do mercado nacional, e desde 2005 passou a atender também o mercado internacional. 
Além de barcos com alto padrão de sofisticação, com bom desempenho propulsivo, o estaleiro oferece aos seus clientes uma infra-estrutura técnica de reparos de embarcações, sendo este um ponto de destaque na sua abordagem com clientes. Os serviços de pós-venda também são priorizados pela empresa, pois ela entende que as necessidades do cliente vão além do momento em que ele adquire uma embarcação.

Atualmente a empresa encontra-se no terceiro lugar entre os estaleiros nacionais com maior índice de produtividade, segundo os entrevistados, após uma análise de mercado entre os principais construtores realizada pela Boat Show 2005, durante o evento, mas o objetivo da empresa é atingir a liderança do mercado nacional de construção de embarcações de esporte recreio até 2015 .
Tais problemas não se restringiam ao setor de produção, pois no setor administrativo também estavam presentes devido à má gestão da informação. Os dados referentes aos clientes, processos de compras de equipamentos eram centralizados e arquivados na sua maioria em papel e a integração com o setor de projetos era deficiente.

Entretanto, nesta fase a empresa dispunha de computadores tanto na produção quanto no departamento de projeto, mas estes não estavam integrados e eram utilizados apenas para atividades pontuais. Brynjolfsson (1993) trata esta questão como sendo um dos aspectos destacados do chamado paradoxo da produtividade em TI, ou seja, os recursos de TI existem, porém, sua má gestão e utilização impedem que as empresas obtenham o retorno esperado.

\section{primeiro obstáculo a ser vencido foi a resistência às mudanças} impostas pelos gerentes e funcionários mais antigos do estaleiro.

\section{Resultado das entrevistas}

Os principais resultados obtidos com as entrevistas realizadas com os vários atores da empresa serão apresentados da seguinte forma: a) situação da empresa antes do uso efetivo da TI; b) resultados obtidos com mudança da equipe e em relação ao uso das aplicações de TI; c) análise dos resultados.

\section{Situação antes da implantação da TI no DNP e GP}

De acordo com os entrevistados, antes da fase de implantação da TI no DNP e GP, o estaleiro Alpha apresentava problemas na produção e falhas nos projetos. O controle do setor de produção era descentralizado e a informação sobre a produção não circulava em todos os departamentos da empresa. Deste modo, não se conhecia efetivamente em que fase de montagem uma embarcação específica estava, e tampouco era possível controlar quem estava desenvolvendo uma determinada atividade e como ela estava sendo trabalhada. Além disso, o desperdício de material era intenso por falta de monitoramento adequado.

Os entrevistados salientaram que qualquer falha em um dos vários processos de construção da embarcação (laminação, pintura, acabamento, montagem e teste) compromete o andamento na linha de montagem, provocando assim atrasos na entrega. Os controles produtivos eram feitos de forma isolada, pois não havia integração da informação, acarretando problemas junto aos fornecedores que, conseqüentemente, atingiam os clientes.

\section{Mudanças no processo de DNP e GP}

De acordo com os entrevistados, para iniciar as mudanças, todos os gerentes dos diversos setores reuniram-se com a diretoria e planejaram as novas estratégias que iriam ser seguidas. As contribuições vieram de todas as partes: diretoria, projeto, marketing, administrativo e produção. Foi apresentado o cenário em que a empresa estava no mercado e foram estabelecidos os objetivos que seriam alcançados com a implantação de um sistema que proporciona aumento de qualidade, produtividade tanto no desenvolvimento quanto no produto final.

Entretanto, o primeiro obstáculo a ser vencido foi a resistência às mudanças impostas pelos gerentes e funcionários mais antigos do estaleiro. Neste sentido, Santos e Sussman (2000) explicam que lidar com este problema não é fácil, tendo em vista que, desde de 1951, pesquisadores tentam descobrir quais as forças que intervêem na resistência a mudanças. No geral, as mudanças nas empresas partem de cima para baixo, ou seja, partem dos gerentes até os subordinados. Este fato explica por que alguns gerentes acham que a mudança representa uma ameaça ou até perda de seus cargos e, em muitos deles, existe a necessidade de "sentir-se competente". Por isso, muitos querem deixar uma marca pessoal em cada projeto, sem questionar sua responsabilidade em caso de atraso ou falha do projeto (SANTOS; SUSSMAN, 2000).

Diante deste quadro, ocorreu uma troca na composição nos quadros de gerência do estaleiro, resultando na contratação de novos gerentes e outros funcionários de chão-de -fábrica com outra mentalidade. Depois de estabelecidas tais mudanças, o foco principal foi melhorar o setor de desenvolvimento de novos produtos.

Assim, as mudanças que ocorreram no DNP foram a instalações de novos softwares, como AUTOCAD, Rhinoceros e Micro Station, para o desenvolvimento de projetos em 2D e 3D e aquisição de computadores mais potentes. 
Conseqüentemente, através do processo de virtualização dos projetos em 3D, os departamentos de vendas, produção e projeto podem analisar as características dos produtos que estão sendo desenvolvidos para seus clientes. As Figuras 5 e 6 apresentam a virtualização do ambiente interno e externo de uma nova embarcação projetada.

É certo que cada projeto tem a suas particularidades, pois depende diretamente do gosto e da necessidade do cliente, conhecendo esta realidade o departamento de projetos criou uma etiqueta eletrônica, que serve de referência para aquele projeto. Esta codificação é anexada pelo departamento de DNP junto com a ordem de serviço desenvolvida pelo departamento administrativo que percorre todo estaleiro.

A ordem de serviço eletrônica também foi uma inovação, pois no passado as informações eram dispersas. Contudo, após esta implantação o trabalho ficou mais dinâmico e as informações são armazenadas no computador. Segundo os entrevistados, no momento em que um novo contrato é fechado, o departamento administrativo gera uma ordem de serviço eletrônica que contém todas as especificações técnicas do produto a ser desenvolvido. Segundo Brynjolfsson (1993), novas tecnologias exigem inicialmente determinado período de tempo para a reestruturação, adaptação e melhora da produtividade. Assim, em um primeiro momento houve resistência de alguns funcionários em aceitar este procedimento, mas hoje eles exigem da gerência a ordem de serviço para o controle da produção.

Os setores de projetos e de produção aplicaram conjuntamente técnicas de gerenciamento e planejamento de projeto com a instalação do Microsoft Project e ferramentas PERT/CPM. O planejamento e acompanhamento do ciclo produtivo ficam expostos no mural em forma de planilha

Figura 5: Virtualização do ambiente interno da embarcação.

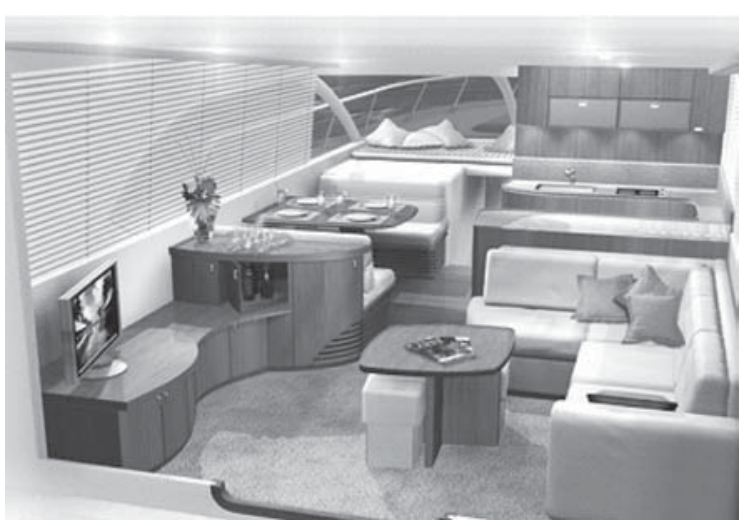

Fonte: Estaleiro Alpha.

Figura 6: Virtualização do ambiente externo da embarcação.

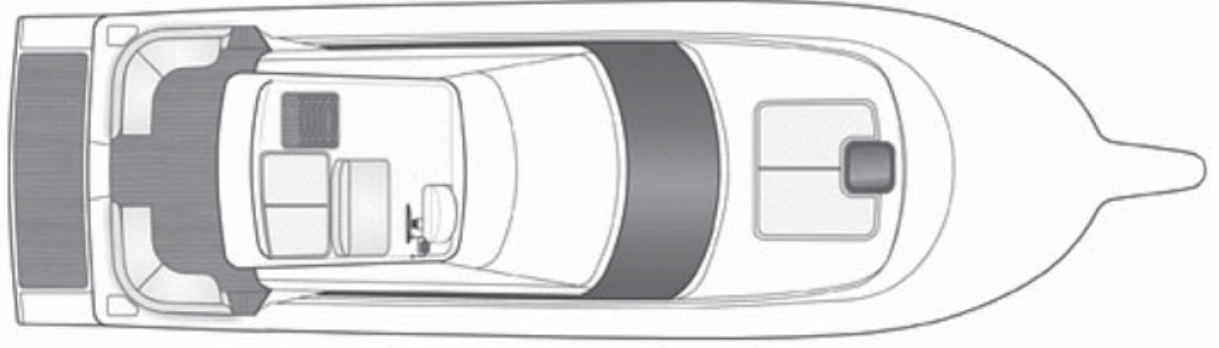

Fonte: Estaleiro Alpha. 
e gráfico, onde todos os funcionários podem acompanhar todas as fases de construção das embarcações que estão na linha de montagem. É importante salientar que uma embarcação de 32 pés, antes da implantação da TI no DNP e GP, necessitava de cerca de seis meses para ser construída e entregue ao cliente; após esta implantação, o tempo foi reduzido para 28 dias. organizacional e cultural que estão alinhadas às estratégias atuais de negócios da empresa.

\section{ANÁLISES DOS RESULTADOS DAS ENTREVISTAS}

Durante as entrevistas realizadas no estaleiro foi possível avaliar o impacto da TI na organização. O motivo pelo qual ocorreram mudanças em relação aos funcionários em todos os níveis pode ser observado segundo demonstração de Santos e Sussman (2000) que explicam como ocorre a velocidade de mudança dentro das organizações, conforme mostrado na Figura 7.

Para estes autores as mudanças de tecnologia ocorrem mais rapidamente do que as do comportamento pessoal, pelo fato de no mercado

Em maio de 2004, foi instalado um servidor que passou a interligar os departamentos da empresa através da intranet. São disponibilizados dados em forma de planilhas com a evolução diária da produção, para que todos os departamentos tenham acesso, criando um elo entre os departamentos. Por exemplo, o departamento de compras pode agendar a entrega de materiais junto aos fornecedores e vendas tem base para programar os prazos de entregas de novos pedidos, pois os dados são atualizados dia-a-dia.

Juntamente com a intranet, a internet também é utilizada como ferramenta de comunicação interna e externa. Através dela os clientes recebem relatórios semanais, onde acompanham a construção da embarcação, através de fotos e planilhas. O setor de qualidade trabalha com câmeras digitais e softwares para tratamento de imagem, que oferecem maior flexibilidade para encontrar possíveis falhas nos processos de acabamento. De acordo com os entrevistados, os investimentos em TI proporcionaram mudanças na estrutura constantemente serem lançadas novas tecnologias que precisam ser rapidamente absorvidas. No caso do estaleiro Alpha não foi diferente: percebeu-se que as mudanças de tecnologia aconteceram muito mais rapidamente do que as alterações de comportamento que, conseqüentemente, refletem na estrutura de trabalho e na execução das tarefas. Nota-se, portanto, que antes das mudanças impostas pelas novas aplicações de TI, a empresa utilizava a TI apenas como suporte para algumas atividades do dia-a-dia. Após sua implementação das novas aplicações, a TI passou a fazer parte da estrutura do estaleiro em todos os setores, permitindo que os controles, desenvolvimento de novos produtos e o planejamento e gerenciamento de projetos trabalhassem de maneira integrada.

Portanto, segundo a classificação de McFarlan (1984), pode-se verificar que o uso da TI na empresa estava enquadrado antes da implementação das novas aplicações como "Suporte". Após seu uso de forma racional, a classificação

Figura 7: Velocidade de mudança.

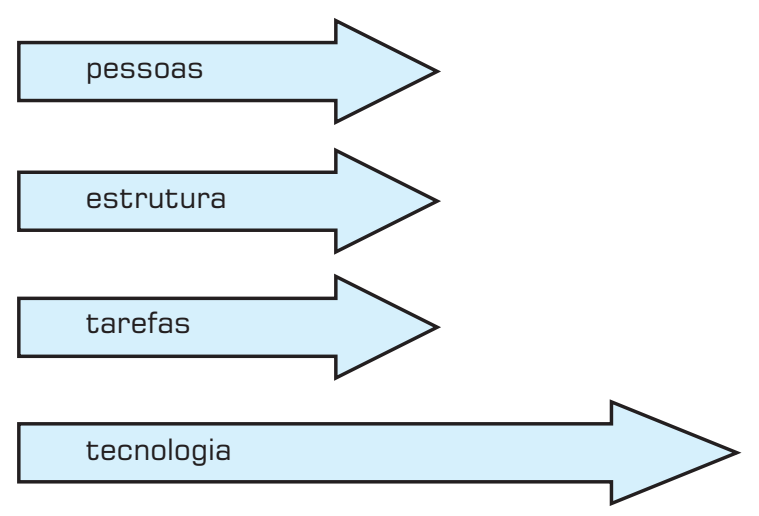


migrou para um estágio de "Transição", pois passou de uma posição modesta para uma de maior destaque na estratégia da empresa, conforme mostrado na Figura 8.

Por outro lado, foi observado que as novas aplicações de TI foram acompanhadas por diversas mudanças nos processos das empresas, tanto no desenvolvimento de produtos, como na fabricação e no controle dos pedidos dos clientes. Este fato corrobora a visão de Farrell (2003), que destacou que a TI pode trazer grandes benefícios quando implementada em conjunto e com alinhamento a mudanças organizacionais.

Novos investimentos em aplicações de TI estão sendo programados para um futuro próximo, como a instalação de um sistema Enterprise Resource Planning - ERP, para integrar por completo todos os departamentos da empresa. Isto se deve aos benefícios gerados pela TI, onde a administração do estaleiro percebeu os retornos do investimento realizado.

Em relação aos FCS do estaleiro Alpha 1, durante a entrevista estes foram identificados e classificados como sendo:

- Design dos produtos;

- Qualidade final e desempenho das embarcações;

- Inovação tecnológica;

- Custos operacionais e de comercialização;

- Assistência técnica;

- Atendimento pós-vendas;

- Prazo de entrega.

\section{CONCLUSÕES}

O estudo de caso apresentado indicou uma mudança na visão da empresa em relação ao uso da TI no DNP e GP, o que causou mudanças profundas no âmbito cultural e organizacional. No primeiro momento a empresa não tinha nenhuma estratégia de TI, mas com o aparecimento de diversos problemas nos setores da empresa, a TI passou a ser utilizada como ferramenta de trabalho intrinsecamente ligada aos negócios. Fica claro que a TI iniciou seu papel como suporte para atividades diárias e, posteriormente, passou a ser um instrumento importante dentro da organização, pois apresentou soluções para problemas internos, proporcionando agilidade, qualidade e rapidez para o estaleiro.

No contexto geral, o envolvimento da alta gerência durante a fase de implementação das novas aplicações de TI foi primordial e, atualmente, o estaleiro está colhendo os frutos do investimento, principalmente no setor de desenvolvimento de novos produtos.

As mudanças no processo de DNP e GP dirigidas pela TI foram fundamentais para sua manutenção neste mercado extremamente competitivo. A criação de modelos virtuais de todos os compartimentos da embarcação auxilia a equipe de DNP a encontrar e corrigir as falhas no projeto, diminuindo as possibilidades de erros na construção e montagem dos componentes.

O estaleiro Alpha alcançou ganhos significativos em economia de tempo e material com processos de simulação e virtualização. Pode-se observar que todos os setores tiveram impacto direto com a implementação da TI, departamento de produção, recursos humanos, qualidade e administrativo. A redução no tempo de construção de uma embarcação de seis meses para vinte oito dias confirma que a TI pode alavancar o crescimento das empresas, e o retorno do investimento em hardware e software torna-se visível em pouco tempo, desde que a TI seja aplicada de maneira correta, alinhada ao planejamento estratégico da empresa.

Por outro lado, os problemas encontrados dentro do estaleiro no que diz respeito ao paradoxo da produtividade, ou seja, à resistência às mudanças nos processos de trabalho, com a implantação da TI foram evidenciados e superados.

Figura 8: Grid estratégico do impacto das aplicações de TI.

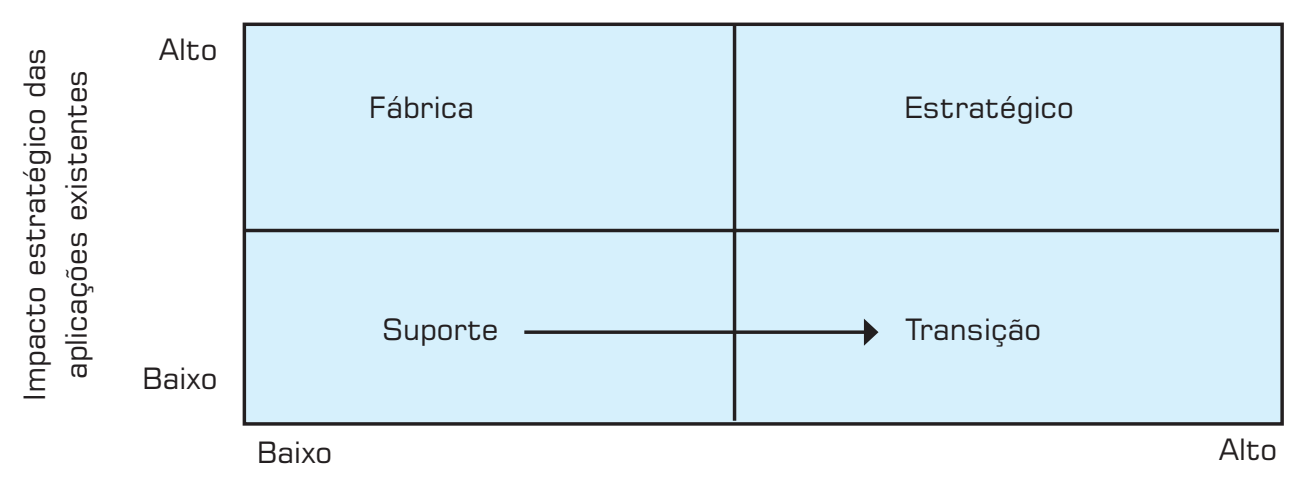


Para isso, foi necessário conscientizar todos os funcionários sobre a forma de utilizar as novas ferramentas e os ganhos produtivos pretendidos com o novo sistema de trabalho. Finalmente, foi observada a importância de aplicações de TI estarem alinhadas com mudanças organizacionais, tendo em vista a obtenção de resultados positivos e significativos. Uma limitação do estudo realizado residiu no fato de que não abordou a quantificação dos investimentos em TI e dos retornos por eles proporcionados. No entanto, esta foi uma opção dos autores, que buscaram focar mais nos aspectos qualitativos dos benefícios auferidos.

Futuros trabalhos deverão explorar outros aspectos do uso da TI na indústria de construção naval, aprofundando os pontos levantados neste presente artigo.

\section{Artigo recebido em 15/06/2005 Aprovado para publicação em 29/03/2007}

\section{neferências \\ ABRAHAM, B.; LEDOLTER, J. Statistical Methods for Forecasting. New York: John Wiley \& Sons, 1983. \\ ALLMENDINGER, E. E. Anais da I semana de estudos sobre transportes maritimos e cons- trução naval: Projeto de Navios Mercantes - Potencial humano necessário. São Paulo: Centro de Engenharia Naval da Escola Politécnica da Universidade de São Paulo, 1960. 607 p.}

BRYNJOLFSSON, E. The productivity paradox of information technology. Communications of the $A C M$, v. 36, n. 12 , p. $67-77,1993$.

BRYNJOLFSSON, E.; HITT, L. M. Beyond the productivity paradox. Communications of the ACM, Aug. 1998

.Computing Productivity: Firm-Level Evidence. Review of Economics and Statistics, p. 793-808, 2003.

CARR, N. IT Doesn't Matter. Harvard Business Review, v. 81, n. 5, p. 41-49, may. 2003.

CLAVER, E; GONZALEZ R.; LLOPIS J. An analysis of research in information systems (1981-1997), Information \& Management, 37, p. 181-195, 2000.

CSILLAG, J. M.; GRAEML, A. R. Os Impactos da Utilização da Internet e Outras Tecnologias da Informação Sobre o Setor Industrial (Uma Análise de Empresas do Estado de São Paulo). Fundação Getúlio Vargas Escola de Administração de Empresas de São Paulo Núcleo de Pesquisas e Publicações, 2004.
CUKIERMAN, Z. S. O Modelo PERT/CPM Aplicado a Projetos. 2. Ed. Rio de janeiro Editora Rio - Sociedade Cultural Ltda, 1982.

DAVENPORT, T.; JARVENPAA, S.; BEERS, M. Improving knowledge process. Center for business innovation. Ernst \& Young LLP, 1995. Disponível em: <http://www. providersedge.com $>$. Acesso em: jun. 2005.

DIAS, M. V. B. Um novo enfoque para o gerenciamento de projetos de desenvolvimento de software. Dissertação (Mestrado) Faculdade de Economia, Administração e Contabilidade da Universidade de São Paulo, São Paulo. 2005.

FARRELL, D. The Real New Economy. Harvard Business Review, v. 81, n. 10, p. 104-112L, October, 2003.

FORD, D. N.; STERMAN, J. D. Overcoming the $90 \%$ Syndrome: Iteration Management in Concurrent Development Projects, 1999. Disponível em: <http://ceprofs. tamu.edu/dford $>$. Acesso em: 10 maio 2005

HALLOWS, J. E. The Project Management Office Toolkit. New York: AMACOM, 2002

INTERGRAPH, PRESS REALISE. White paper. An Information Technology Blueprint for the Twenty first Century Amphibious Warship, 2004. Disponível em: <http:// solutions.intergraph.com $>$. Acesso em 10 maio 2005

JONS, O. P. Preservation and restoration of historic vessels in virtual environments: Maritime. Park Association, junho, 1997.
Disponível em: <http://www.maritime. org/conf/confjons. htm>. Acesso em: 10 maio 2005.

JURAN, J. M. A. Qualidade desde o projeto: Os novos passos para o planejamento da qualidade em produtos e serviços. São Paulo: Pioneira, 1992.

KROO, I. Computational-based design. White paper. 1996. Disponível em: http:// aero.stanford.edu/ComputationalDesign. html. Acesso em: 25 jan. 2004.

LAUDON, K. C.; LAUDON, J. P. Sistemas de Informação Gerenciais. São Paulo: Pearson, 2004.

LAURINDO, F. J. B. Tecnologia da Informação como suporte às estratégias empresariais. In: AMATO NETO, JOÃO (coord.) Redes entre organizações eficácia nas organizações. São Paulo: Editora Atlas, p. 240-257, 2005.

LAURINDO, F. J. B., CARVALHO, M. M. Changing product development process through information technology: a Brazilian case. Journal of Manufacturing Technology Management (novo nome do Integrated Manufacturing Systems), v. 16, n. 3, 2005.

LUFTMAN, J. N. Ed. Competing in the Information Age - Align in the Sand. New York: Oxford University Press. 2003. $413 \mathrm{p}$.

LUTCHEN, M.D. Managing IT as a Business. Hoboken: John Wiley; Sons, Inc, 2004. $242 \mathrm{p}$
MACDONALD, S.; ANDERSON, P.; KIMBEL, D. Measurement or Management?: Revisting the Productivity Paradox of Information Technology. Vierteljahrshefte zur Wirtschaftsforschung, 69, p. 601-617. 2000

MACHADO, L. S. A realidade virtual no modelamento e simulação de procedimentos invasivos em oncologia pediátrica: um estudo de caso no transplante de medula óssea. Tese (Doutorado) - Escola Politécnica - Departamento de Sistemas Eletrônicos da Universidade de São Paulo, São Paulo, 2003.

MCFARLAN, W. E. The 1990's: The Information Decade. Bussines Quarterly, v. 55, n. 1, p. 73-79, Summer 1990.

MCGOVERAN, D. An Introduction to BPM \& BPMS. Business Integration Journal, April, 2004.

MORAES, R.O.; LAURINDO, F.J.B. Um estudo de caso de gestão de portfolio de projetos de tecnologia da informação. Gestão \& Produção, v. 10, n. 3, p. 311-328, dez. 2003

NBR ISO 10006. Gestão da Qualidade Diretrizes para a qualidade no gerenciamento de projetos. ABNT - Associação Brasileira de Normas Técnicas, 2000.

NOLAN, R. L.; MCFARLAN, W. E. Information Technology and the Board of Directors. Harvard Business Review, v. 83 , n. 10 , p. $96-106$, Oct. 2005 


\section{- Referências}

OLIVEIRA, R. C. F. Gerenciamento de projetos e a aplicação da análise de valor agregado em grandes projetos. Dissertação (Mestrado) - Escola Politécnica - Departamento de Engenharia Naval da Universidade de São Paulo: São Paulo, 2003.

PAPANEK, V. Design for the Real World: Human Ecology and Social Change. New York: Pantheon Books, 1971.

PATAH, L. A. Alinhamento estratégico de estrutura organizacional de projetos: Uma análise de múltiplos casos. Dissertação (Mestrado) - Escola Politécnica da Universidade de São Paulo. Departamento de Engenharia de Produção, São Paulo, 2004

PEREIRA, N. N.; LAURINDO, F. J. B. A tecnologia da informação como suporte à indústria de construção naval: Um estudo de caso. XXV ENEGEP 2005 Encontro Nacional de Engenharia de Produção, 2005, Porto Alegre. Anais XXV ENEGEP 2005. Porto Alegre: UFRGS, v. 1. p. $1-8,2005$ novos produtos na indústria de construção naval: um estudo de caso. Anais $3^{\circ}$ CONTECSI Congresso Internacional de Gestão de Tecnologia e Sistemas de Informação. TECSI FEA USP, p. 2056 2075, FEA-USP, São Paulo, 2006

PEREIRA, N N : SAMPAIO, C. M. P, Proposta de implantação de transporte de álcool pela hidrovia TietêParaná. IV Seminário de Transporte Desenvolvimento Hidroviário Interior. Belém, Agosto, 2005

PROJECT MANAGEMENT INSTITUTE PMI. PMBOK guide: Um guia do conjunto de conhecimentos do gerenciamento de projetos. Project Management Institute, 2000.

PORTER, M.E; MILLAR, V. How Information Gives you Competitive Advantage. Harvard Business Review, p. 149-160, 1985.

PORTER, M. E. Competitive in Global Industries. Ed. Michael E. Porter,, 1986.
PORTER, M. E. Strategy and the internet, Harvard Business Review, v. 79, n. 1, p. 63-78, 2001.

POSSAMAI, O.; FUTAMI, A. H.; VALENTINA, L. V. O. D. A Model of Knowledge Management to Improve the Quality of The Product. Product Management \& Development. Revista Brasileira de Gestão e Desenvolvimento de Produto. 2002. Disponível em: < http://www.ctc.ufsc. br>. Acesso em: 16 maio 2005.

ROCKART, J. F. Chief executives define their own data needs. Harvard Business Review, v. 57, n. 2, p. 81-92, Mar/Apr. 1979.

RABECHINI JR., R.; CARVALHO, M. M.; LAURINDO, F. J. B. Fatores críticos para implementação de gerenciamento por projetos: o caso de uma organização de pesquisa. Revista Produção, São Paulo, v. 12, n. 2, 2002.

SANTOS, B.; SUSSMAN, L. Improving the return of IT investment: the productivity paradox. International Journal of Information, 2000
TAN K. T.; BLIGH, T. P. A New Approach to an Integrated CAD Method for Surface Ship Design. Naval Engineers Journal, January 1998.

TEIXEIRA, J. C. Applying Design Knowledge to Create Innovative Business Opportunities - Institute of Design Illinois Institute of Technology, 2000.

TUMAN, G. J. Development and Implementation of Effective Project Management Information and Contro Systems. Em CLELAND D. I.; KING, W. R. Project Management Handbook. New York: Van Nostrand Reinhold, 1983.

TURBAN, E.; MCLEAN, E.; WETHERBE, J. Tecnologia da Informação para Gestão. 3. Ed. Porto Alegre: Bookman, 2004.

WOODHAM, J. M. Twentieth-Century Design. Oxford: Oxford University Press, 1997.

YIN, R. Case study research: design and methods. Newbury Park, Sage Pub, 1991.

\section{Agradecimentos}

Os autores agradecem ao CNPq - Conselho Nacional de Desenvolvimento Científico e Tecnológico - e à ANP - Agência Nacional de Petróleo - pelo apoio financeiro parcial concedido às suas pesquisas.

\section{- Sobre os autores}

\section{Prof. MSe. Newton Narciso Pereira}

Professor do Centro Universitário Monte Serrat - Santos

End.: Rua Olho d'Água do Borges, 199 bloco 2 - ap. 23 - 03820 - 000 - São Paulo - SP - BRASIL

Tel.: 55 (11) $9630-8789-3091-5350-\operatorname{ramal} 217$

Fax: 55 (11) 3150-6999

E-mail: newtonnaval@gmail.com - newton.pereira@usp.br

\section{Prof. Dr. Fernando José Barbin Laurindo}

Professor Associado do Departamento de Engenharia de Produção da Escola Politécnica da Universidade de São Paulo Av. Prof. Almeida Prado, 128, Tr. 2 Biênio, 2o andar - 05508-900 - São Paulo - SP - BRASIL

Tel.: 55 (11) 3091-5363 - ramal 454

Fax: 55 (11) 30915399

E-mail: fjblau@usp.br 